Article DOI: https://doi.org/10.35219/im.2018.2.06

\title{
A PARALLEL BETWEEN THE SEVEN MEASUREMENT METHODS OF VIBRATION TRANSMITTED TO THE HAND-ARM SYSTEM
}

\author{
Prof. PhD. Habil. Mihaela Picu, Fiz. Drd. \\ Laurentiu Picu \\ "Dunarea de Jos" University of Galati
}

\begin{abstract}
In the case of workers performing a series of activities involving the use of equipment that transmit vibrations to the hands, there is a risk of getting sick. In this paper, we will calculate the daily exposure for a worker who uses for the same operation, in 2 different days: i) angular grinder, angular milling machine and hammer-chisel, from certain manufacturers; ii) same tools from other manufacturers. The methods of calculating daily exposure are: a) Calculation of daily exposure using partial vibration exposures and the duration of each source; b) The "traffic light" system; c) Daily exposure graph; d) Exposure points system; e) Nomogram of daily exposure; f) Calculation of daily exposure using exposure points; g) Methods that use the Internet. After performing all the calculations, it was found that the fastest and most accurate method is the one that uses the Internet: "Hand-arm vibration exposure calculator", because it instantly gives all values of interest.
\end{abstract}

KEYWORDS: hand-arm vibration, exposure action value, exposure limit value, angular grinder, angular milling machine and hammer-chisel

\section{INTRODUCTION}

In the case of workers performing a series of activities involving the use of equipment (chainsaws, chipping hammers, clearing saws, demolition hammers, grinders, impact drills, impact wrenches, needle scalers, rammers, road breakers, rock drills, sanders, saws, vibratory rammers) (fig. 1) that transmit vibrations to the hands, there is a risk of getting sick. Depending on the size of the vibrations, the frequency and the exposure duration, these can lead to different diseases over time: vascular (deterioration of blood vessels, e.g white finger disease through vibration), neuropathic (nerve/ nervous system damage), tendonitis or carpal tunnel syndrome. The European Union has issued Directive 2002/44/EC on the minimum health and safety requirements regarding the exposure of workers to the risks arising from physical agents (vibrations) [1, 2], introducing the following vibration limits transmitted to the hand-arm system:

- The exposure action value (EAV) is a daily amount of vibration exposure above which employers are required to take action to control exposure (a fost stabilită la $2.5 \mathrm{~m} / \mathrm{s}^{2}$ ).

-The exposure limit value (ELV) is the maximum amount of vibration an employee may be exposed to on any single day (a fost stabilită la 5 $\left.\mathrm{m} / \mathrm{s}^{2}\right)$. Both values are $\mathrm{A}(8)$ values, which means that they are average vibration values over an 8hour working day.

Before any calculation, must be accurately measured the time during which a worker uses a vibrating tool, as it has been found that this time is overestimated; it is important to know whether the use of that equipment is continuous (using a grinder to remove large amounts of material) or intermittent (using an impact wrench to tighten 
the wheel nuts on vehicles). Vibration must be measured on the three axes (fig. 2).

For HAV, the most important equipment frequencies are between $8 \mathrm{~Hz}$ and $1000 \mathrm{~Hz}$. But the disorders caused by vibrations do not occur at all the frequencies which is why the weighted frequency is used. It was found that the weighted acceleration decreases with increasing frequency. In this case, there is a single frequency weighting curve for all three axes.

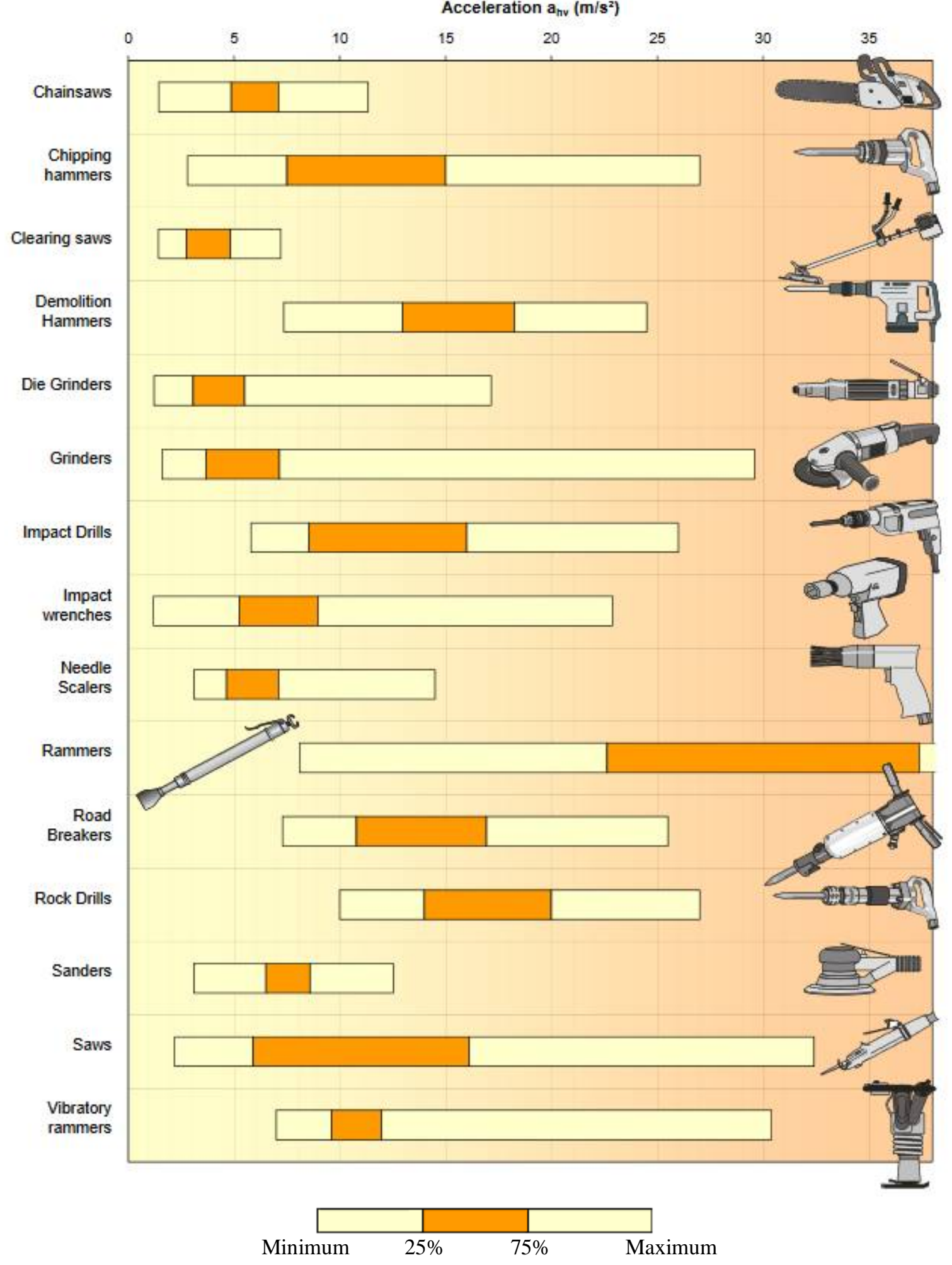

Figure 1. Examples of vibration magnitudes for common tools

Ranges of vibration values for common equipment on the EU market [1] 


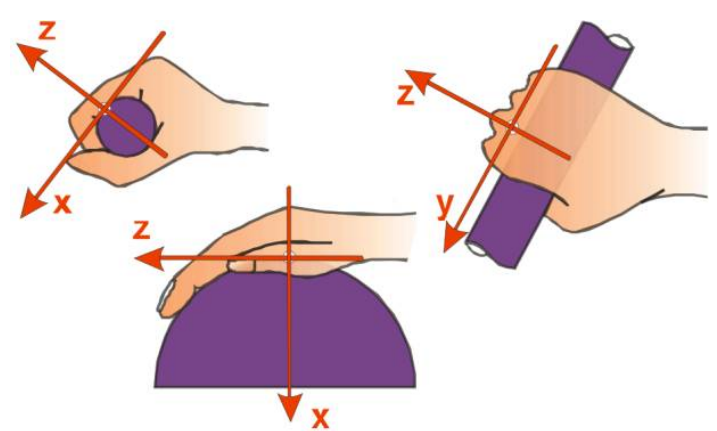

Figure 2. Axes of hand-arm vibration measurement [2]

The total value of the frequency-weighted acceleration $\left(a_{h v}\right)$ is given by the root of the sum of squares of the frequency-weighted acceleration on the three orthogonal axes, x, y and $\mathrm{z}\left(\mathrm{a}_{\mathrm{hvx} / \mathrm{y} / \mathrm{z}}\right)[3]$ :

$$
a_{h v}=\left(a_{h v x}{ }^{2}+a_{h v y}{ }^{2}+a_{h v z}{ }^{2}\right)^{1 / 2}
$$

Manufacturers of such equipment are required to write the appropriate series on the tools: for example, the EN ISO 8662 series for pneumatic and non-electric tools [4] and the IEC 60745 series for electric tools [5], in order to estimate daily exposure and risk assessment. But at present, vibration test codes tend to underestimate the vibrations of the tools and are usually based on measurements on a single axis of vibration. For this reason, it is recommended to multiply by a factor, depending on the type of tool: Combustion engine tools: $\mathrm{x} 1$; Pneumatic tools: $\mathrm{x} 1.5$ to $\mathrm{x} 2$; Electric tools: $\mathrm{x} 1.5$ to $\mathrm{x} 2$.

\section{METHODS OF CALCULATING THE DAILY EXPOSURE}

There are several methods of calculating the daily exposure. Some that do the calculation directly on the internet while others that use charts, nomograms or the exposure points system [2].

In this paper, we will calculate the daily exposure for a worker who uses for the same operation, in 2 different days:

i) angular grinder, angular milling machine and hammer-chisel, from certain manufacturers,

ii) same tools from other manufacturers.

- On the first day, the worker used the tools as follows:

1) An angle grinder: $a_{h v 1}=3.8 \mathrm{~m} / \mathrm{s}^{2}$ for $T_{1}=1$ hour and 45 minutes;

2) An angle cutter for $a_{h v 2}=2.9 \mathrm{~m} / \mathrm{s}^{2}$ for $T_{2}=1$ hour and 15 minutes;

3) A chipping hammer $a_{h v 3}=8.4 \mathrm{~m} / \mathrm{s}^{2}$ for $T_{3}=20$ minutes.
- The next day, the worker used the tools as follows:

4) An angle grinder: $a_{\mathrm{h} v 4}=4.6 \mathrm{~m} / \mathrm{s}^{2}$ for $\mathrm{T}_{4}=1$ hour and 30 minutes;

5) An angle cutter for $a_{h v 5}=3.5 \mathrm{~m} / \mathrm{s}^{2}$ for $T_{5}=1$ hour;

6) A chipping hammer $a_{h v 6}=15.5 \mathrm{~m} / \mathrm{s}^{2}$ for $T_{6}=15$ minutes.

a) Calculation of daily exposure using partial vibration exposures and the duration of each source [6]:

i) for the first day: the partial vibration exposures for the three tasks are:

$$
\begin{aligned}
& \text { 1) } \quad A_{\text {grin }}(8)=a_{h v l} \sqrt{\frac{T_{1}}{T_{0}}}=1.7772 \mathrm{~m} / \mathrm{s}^{2} \\
& \text { 2) } \quad A_{\text {cutt }}(8)=a_{h v 2} \sqrt{\frac{T_{2}}{T_{0}}}=1.1463 \mathrm{~m} / \mathrm{s}^{2} \\
& \text { 3) } \quad A_{\text {chip }}(8)=a_{h v 3} \sqrt{\frac{T_{3}}{T_{0}}}=1.7146 \mathrm{~m} / \mathrm{s}^{2} \\
& A_{l}^{2}(8)=A_{\text {grin }}{ }^{2}(8)+A_{\text {cutt }}^{2}(8)+A_{\text {chip }}{ }^{2}(8)=7.4124 \\
& A_{l}(8)=2.7225 \mathrm{~m} / \mathrm{s}^{2}
\end{aligned}
$$

ii) for the second day:

$$
\begin{aligned}
& \text { 4) } A_{\text {grin }}(8)=a_{h v 4} \sqrt{\frac{T_{4}}{T_{0}}}=1.9918 \mathrm{~m} / \mathrm{s}^{2} \\
& \text { 5) } \quad A_{\text {cutt }}(8)=a_{h v 5} \sqrt{\frac{T_{5}}{T_{0}}}=1.2374 \mathrm{~m} / \mathrm{s}^{2} \\
& \text { 6) } A_{\text {chip }}(8)=a_{h v 6} \sqrt{\frac{T_{6}}{T_{0}}}=2.74 \mathrm{~m} / \mathrm{s}^{2} \\
& A_{2}^{2}(8)=A_{\text {grin }}{ }^{2}(8)+A_{\text {cutt }}{ }^{2}(8)+A_{\text {chip }}{ }^{2}(8)=13.0061 \\
& A_{2}(8)=3.6063 \mathrm{~m} / \mathrm{s}^{2}
\end{aligned}
$$

On both days, each tool generates vibrations below the exposure action value area $\left(\mathrm{EAV} \rightarrow 2.5 \mathrm{~m} / \mathrm{s}^{2}\right)$ if taken separately, but if summed up, as it is in reality, it is obtained for the first day $A_{1}(8)=2.7225 \mathrm{~m} / \mathrm{s}^{2}$, respectively $\mathrm{A}_{2}(8)=3.6063 \mathrm{~m} / \mathrm{s}^{2}$, meaning higher than the exposure action value, but lower than the exposure limit value $\left(\mathrm{ELV} \rightarrow 5 \mathrm{~m} / \mathrm{s}^{2}\right)$.

b) The "traffic light" system

Some manufacturers of tools that transmit vibrations to the hand-arm system have developed a "traffic light" system, so that each worker can read directly on the tool the magnitude of the vibrations they will face (Tab. $1)$. In the analysed cases it is found that $A_{1}(8)$ and $\mathrm{A}_{2}(8)$ are found in the yellow zone. 
Table 1. Example of colour coding scheme for

\begin{tabular}{|c|c|c|}
\hline $\begin{array}{l}\text { Colour } \\
\text { code }\end{array}$ & $\begin{array}{l}\text { Time to reach } \\
\text { EAV }\left(2.5 \mathrm{~m} / \mathrm{s}^{2}\right)\end{array}$ & $\begin{array}{l}\text { Time to reach } \\
\operatorname{ELV}\left(5 \mathrm{~m} / \mathrm{s}^{2}\right)\end{array}$ \\
\hline Red & $\begin{array}{l}\text { Less than } \\
30 \text { minutes }\end{array}$ & $\begin{array}{c}\text { Less than } \\
2 \text { hours }\end{array}$ \\
\hline Yellow & $\begin{array}{l}30 \text { minutes } \\
\text { to } 2 \text { hours }\end{array}$ & $\begin{array}{l}2 \text { hours } \\
\text { to } 8 \text { hours }\end{array}$ \\
\hline Green & $\begin{array}{l}\text { More than } \\
2 \text { hours }\end{array}$ & $\begin{array}{l}\text { More than } \\
8 \text { hours }\end{array}$ \\
\hline
\end{tabular}

c) Daily exposure graph

To be able to observe quickly, but with a certain approximation, which is the daily exposure of a worker to the vibrations generated by a particular tool, it is sufficient to unite the line that rises from the horizontal axis (exposure time) with the one that rises from the vertical axis (vibration magnitude) and find out in which area they intersect. Starting from this area toward the right vertical axis, you can find the value $A(8)$. For the 2 studied cases (fig. 3 ):

- The black lines: For Eq 1, the intersection occurs at approximately 1.5 to $2 \mathrm{~m} / \mathrm{s}^{2}$ (from calculations: $\left.\mathrm{A}(8)=1.7772 \mathrm{~m} / \mathrm{s}^{2}\right)$; For $\mathrm{Eq} \mathrm{2}$, the intersection occurs at approximately 1 to 1.5 $\mathrm{m} / \mathrm{s}^{2}$ (from calculations: $\mathrm{A}(8)=1.1463 \mathrm{~m} / \mathrm{s}^{2}$ ); For $\mathrm{Eq} \mathrm{3,} \mathrm{the} \mathrm{intersection} \mathrm{occurs} \mathrm{at}$ approximately 1 to $1.5 \mathrm{~m} / \mathrm{s}^{2}$ (from calculations: $\left.\mathrm{A}(8)=1.7146 \mathrm{~m} / \mathrm{s}^{2}\right)$.

- The white lines: For Eq 4, the intersection occurs at $2 \mathrm{~m} / \mathrm{s}^{2}$ (from calculations: $\mathrm{A}(8)=$ $\left.1.9918 \mathrm{~m} / \mathrm{s}^{2}\right)$; For $\mathrm{Eq} 5$, the intersection occurs at approximately 1 to $1.5 \mathrm{~m} / \mathrm{s}^{2}$ (from calculations: $\left.\mathrm{A}(8)=1.2374 \mathrm{~m} / \mathrm{s}^{2}\right)$; For Eq 6, the intersection occurs at approximately 2.5 to 3 $\mathrm{m} / \mathrm{s}^{2}$ (from calculations: $\mathrm{A}(8)=2.74 \mathrm{~m} / \mathrm{s}^{2}$ ).

Here too, is seen that $A_{1}(8)$ and $A_{2}(8)$ are in the yellow area.

\section{d) Exposure points system}

Another relatively simple method for analysing vibrations transmitted to the handarm system is to calculate the number of exposure points accumulated in an hour $\left(\mathrm{P}_{\mathrm{E}, 1 \mathrm{~h}}\right.$ in points per hour) [7]:

$$
P_{E, 1 h}=2 a_{h v}^{2}
$$

The correspondence between these values is:

- For the exposure action value $(\mathrm{EAV}) \rightarrow 2.5$ $\mathrm{m} / \mathrm{s}^{2} \rightarrow 100$ points.

- For the exposure limit value $(\mathrm{ELV}) \rightarrow 5 \mathrm{~m} / \mathrm{s}^{2}$ $\rightarrow 400$ points.

The number of exposure points, $\mathrm{P}_{\mathrm{E}}$, is [7]:

$$
P_{E}=\left(\frac{a_{h v}}{2.5 m / s^{2}}\right)^{2} \cdot \frac{T}{8 h} \cdot 100
$$

where $\mathrm{a}_{\mathrm{h} v}$ is the vibration magnitude $\left(\mathrm{m} / \mathrm{s}^{2}\right)$ and $\mathrm{T}$ is the exposure time $(\mathrm{h})$. For the studied cases, the numbers of exposure points are:

$$
\begin{gathered}
P_{E}=\left(\frac{3.8}{2.5}\right)^{2} \cdot \frac{1.75}{8} \cdot 100=50.54 \text { points } \\
P_{E}=\left(\frac{2.9}{2.5}\right)^{2} \cdot \frac{1.25}{8} \cdot 100=21.025 \text { points } \\
P_{E}=\left(\frac{8.4}{2.5}\right)^{2} \cdot \frac{20 / 60}{8} \cdot 100=47.04 \text { points }
\end{gathered}
$$

Total day $1=50.54+21.025+47.04=$ 118.605 points.

$$
\begin{gathered}
P_{E}=\left(\frac{4.6}{2.5}\right)^{2} \cdot \frac{1.5}{8} \cdot 100=63.48 \text { points } \\
P_{E}=\left(\frac{3.5}{2.5}\right)^{2} \cdot \frac{1}{8} \cdot 100=24.5 \text { points } \\
P_{E}=\left(\frac{15.5}{2.5}\right)^{2} \cdot \frac{0.25}{8} \cdot 100=120.125 \text { points } \\
\text { Total day } 2=63.48+24.5+120.125= \\
208.48 \text { points. }
\end{gathered}
$$

\section{e) Nomogram of daily exposure}

On the nomogram in fig. 4 , is drawn a line that unites the magnitude of the vibration with the exposure time. From the intersection with the middle line, one can obtain the partial exposures (on the left) and the number of corresponding points (on the right).

- The black lines: For the line 1, the intersection occurs at about $1.75 \mathrm{~m} / \mathrm{s}^{2}$, respectively 50 points; For the line 2, the intersection occurs at about $1.15 \mathrm{~m} / \mathrm{s}^{2}$, respectively 20 points; For the line 3, the intersection occurs at about $1.7 \mathrm{~m} / \mathrm{s}^{2}$, respectively 45 points. Total $=115$ points.

- The blue lines: For the line 4, the intersection occurs at about $2 \mathrm{~m} / \mathrm{s}^{2}$, respectively 65 points; For the line 5 , the intersection occurs at about $1.2 \mathrm{~m} / \mathrm{s}^{2}$, respectively 25 points; For the line 6 , the intersection occurs at about $3.1 \mathrm{~m} / \mathrm{s}^{2}$, respectively 165 points. Total $=255$ points.

Meaning:

\section{Day 1}

1) $\mathrm{A}_{\text {grin }}(8)=1.75 \mathrm{~m} / \mathrm{s}^{2}$

2) $\mathrm{A}_{\text {cutt }}(8)=1.15 \mathrm{~m} / \mathrm{s}^{2}$

3) $\mathrm{A}_{\text {chip }}(8)=1.7 \mathrm{~m} / \mathrm{s}^{2}$ $\mathrm{A}_{1}(8)=2.6972 \mathrm{~m} / \mathrm{s}^{2}$

50 points

20 points

45 points

115 points 
Day 2

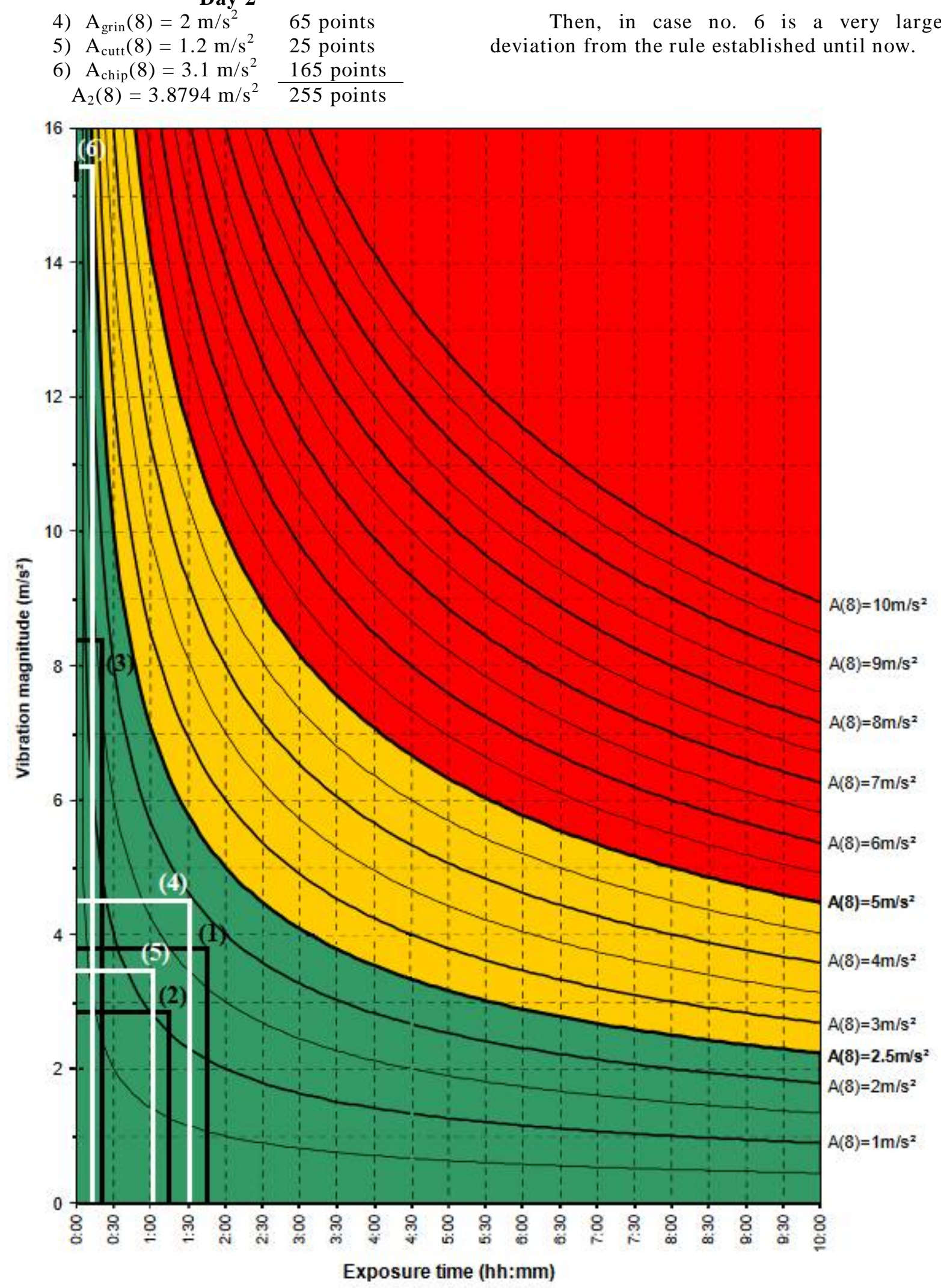

Figure 3. Daily exposure graph the black lines correspond to day 1; the white lines correspond to day 2 [2] 


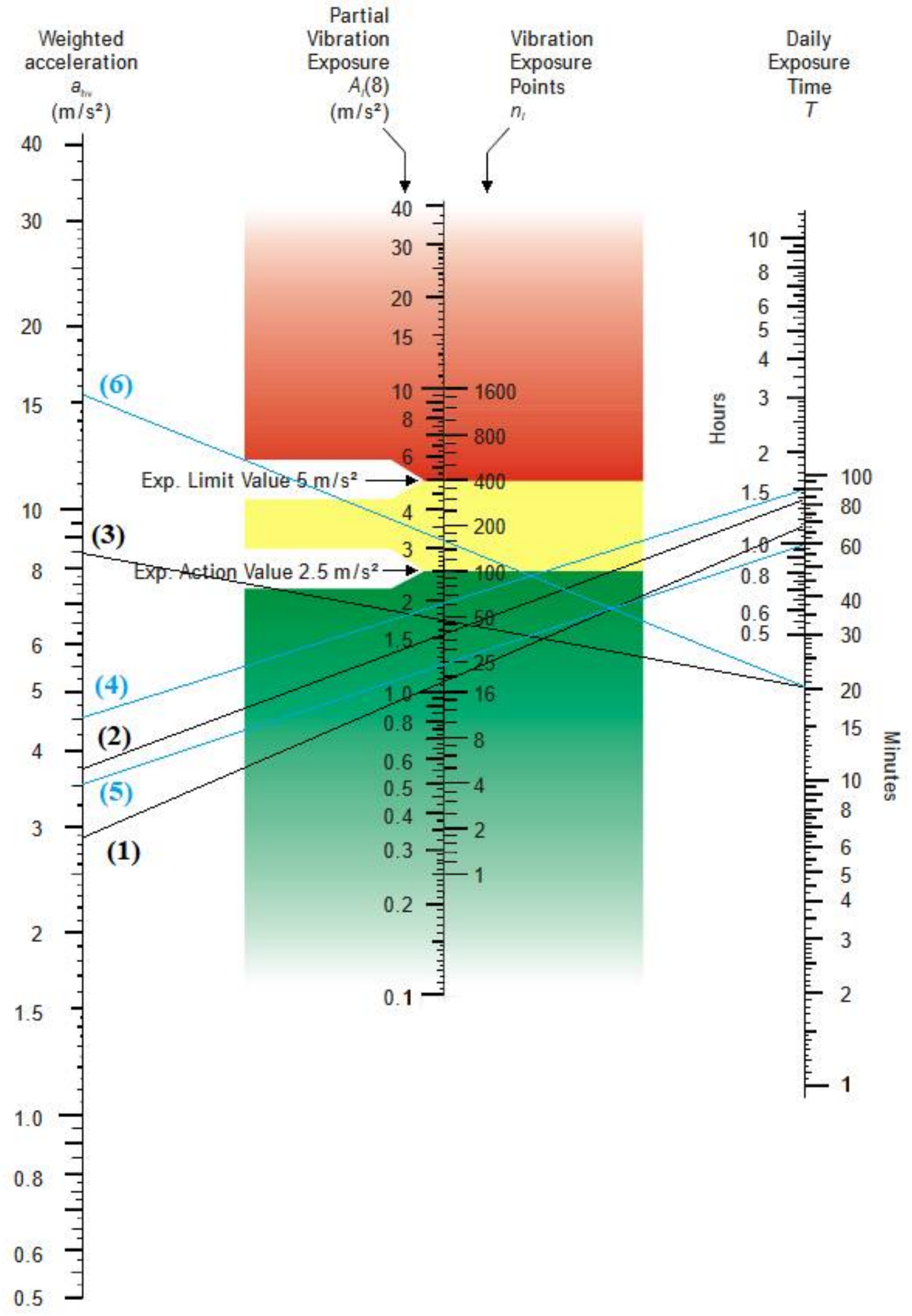

Figure 4. Nomogram of daily exposure of the hand-arm system the black lines correspond to day 1; the blue lines correspond to day 2 [2] 


\begin{tabular}{|c|c|c|c|c|c|c|c|c|c|c|c|c|}
\hline & 20 & 67 & 200 & 400 & 800 & 1600 & 2400 & 3200 & 4000 & 4800 & 6400 & 8000 \\
\hline & 19.5 & 63 & 190 & 380 & 760 & 1500 & 2300 & 3050 & 3800 & 4550 & 6100 & 7600 \\
\hline & 19 & 60 & 180 & 360 & 720 & 1450 & 2150 & 2900 & 3600 & 4350 & 5800 & 7200 \\
\hline & 18.5 & 57 & 170 & 340 & 685 & 1350 & 2050 & 2750 & 3400 & 4100 & 5500 & 6850 \\
\hline & 18 & 54 & 100 & 325 & 650 & 1300 & 1950 & 2600 & 3250 & 3900 & 5200 & 6500 \\
\hline & 17.5 & 51 & 155 & 305 & 615 & 1250 & 1850 & 2450 & 3050 & 3700 & 4900 & 6150 \\
\hline & 17 & 48 & $1+5$ & 290 & 580 & 1150 & 1750 & 2300 & 2900 & 3450 & 4600 & 5800 \\
\hline & 16.5 & 45 & 135 & 270 & 545 & 1100 & 1650 & 2200 & 2700 & 3250 & 4350 & 5450 \\
\hline & 16 & 43 & 130 & 255 & 510 & 1000 & 1550 & 2050 & 2550 & 3050 & 4100 & 5100 \\
\hline & 15.5 & 40 & 120 & 10 & 480 & 960 & 1450 & 1900 & 2400 & 2900 & 3850 & 4800 \\
\hline & 15 & 38 & 15 & 225 & 450 & 900 & 1350 & 1800 & 2250 & 2700 & 3600 & 4500 \\
\hline & 14.5 & 35 & 05 & 910 & 420 & 840 & 1250 & 1700 & 2100 & 2500 & 3350 & 4200 \\
\hline & 14 & 33 & 98 & 195 & 390 & 785 & 1200 & 1550 & 1950 & 2350 & 3150 & 3900 \\
\hline & 13.5 & 30 & 91 & 180 & 365 & 730 & 1100 & 1450 & 1800 & 2200 & 2900 & 3650 \\
\hline & 13 & 28 & 35 & 170 & 340 & 675 & 1000 & 1350 & 1700 & 2050 & 2700 & 3400 \\
\hline on & 12.5 & 26 & 78 & 155 & 315 & 625 & 940 & 1250 & 1550 & 1900 & 2500 & 3150 \\
\hline E & 12 & 24 & 72 & 445 & 290 & 575 & 865 & 1150 & 1450 & 1750 & 2300 & 2900 \\
\hline 등 & 11.5 & 22 & 36 & 130 & 265 & 530 & 795 & 1050 & 1300 & 1600 & 2100 & 2650 \\
\hline تِّ & 11 & 20 & 31 & 120 & 240 & 485 & 725 & 970 & 1200 & 1450 & 1950 & 2400 \\
\hline$\frac{\bar{\sigma}}{0}$ & 10.5 & 18 & 55 & 110 & 220 & 440 & 660 & 880 & 1100 & 1300 & 1750 & 2200 \\
\hline త్ర & 10 & 17 & 50 & 100 & 200 & 400 & 600 & 800 & 1000 & 1200 & 1600 & 2000 \\
\hline$<$ & 9.5 & 15 & 45 & 90 & 180 & 360 & 540 & 720 & 905 & 1100 & 1450 & 1800 \\
\hline & 9 & 14 & 41 & 81 & 160 & 325 & 485 & 650 & 810 & 970 & 1300 & 1600 \\
\hline & 8.5 & 12 & 0 & 72 & 145 & 290 & 435 & 580 & 725 & 865 & 1150 & 1450 \\
\hline & 8 & 11 & 32 & 64 & 130 & 200 & 385 & 510 & 640 & 770 & 1000 & 1300 \\
\hline & 7.5 & 9 & 28 & 56 & 115 & 225 & 340 & 450 & 565 & 675 & 900 & 1150 \\
\hline & 7 & 8 & 25 & 49 & 98 & 405 & 295 & 390 & 490 & 590 & 785 & 980 \\
\hline & 6.5 & 7 & 21 & 42 & 85 & 170 & 255 & 340 & 425 & 505 & 675 & 845 \\
\hline & 6 & 6 & 18 & 36 & 72 & 145 & 215 & 290 & 360 & 430 & 575 & 720 \\
\hline & 5.5 & 5 & 15 & 30 & 61 & 120 & 180 & 240 & 305 & 365 & 485 & 605 \\
\hline & 5 & 4 & 13 & 25 & 50 & 100 & 150 & 200 & 250 & 300 & 400 & 500 \\
\hline & 4.5 & $\hat{v}$ & iv & & $\because i$ & 81 & 120 & 160 & 205 & 245 & 325 & 405 \\
\hline & 4 & & 0 & & 2 & 64 & 96 & 130 & 160 & 190 & 255 & 320 \\
\hline & 3.5 & n & a & in & 25 & 49 & 74 & 98 & 125 & 145 & 195 & 245 \\
\hline & 3 & $z$ & 5 & 5 & 18 & 36 & 54 & 72 & 90 & 110 & 145 & 180 \\
\hline & 2.5 & $\overline{1}$ & $\overline{3}$ & 6 & 13 & 25 & 38 & 50 & 63 & 75 & 100 & 125 \\
\hline & & $5 \mathrm{~m}$ & $15 \mathrm{~m}$ & $30 \mathrm{~m}$ & $1 \mathrm{~h}$ & $2 \mathrm{~h}$ & 3h & $4 \mathrm{~h}$ & $5 \mathrm{~h}$ & $6 h$ & $8 \mathrm{~h}$ & $10 \mathrm{~h}$ \\
\hline & & & & & & iily & po: & time & & & & \\
\hline
\end{tabular}

Figure 5. Exposure points table (rounded values).

the black line corresponds to day 1 ; the white line corresponds to day 2 [2]

f) Calculation of daily exposure using exposure points

In this case, is drawn a line corresponding to the acceleration value and intersects with the line corresponding to the exposure time value. If these values are not found on the graph in fig. 5, they are approximated by the higher value of both acceleration and time. i) for the first day (black line): the partial vibration exposures for the three tasks correspond to the number of points: $64+18+$ $72=154$ points.

ii) for the second day (white line): the partial vibration exposures for the three tasks correspond to the number of points: $81+25+$ $120=226$ points.

Both values (154 points and 226 points) correspond to the yellow zone. 
g) Methods that use the Internet

In order to quickly and accurately assess the degree of exposure to HAV, the "Hand-arm vibration exposure Calculator" (Health \& Safety Executive HAV calculator [8]) was developed. Tools or process name, vibration magnitude and exposure duration are introduced in this computer; it will calculate the exposure points/hour, time to rich $\operatorname{EAV}\left(2.5 \mathrm{~m} / \mathrm{s}^{2}\right)$ and time to rich $\operatorname{ELV}\left(5 \mathrm{~m} / \mathrm{s}^{2}\right)$, as well as partial exposure (in $\mathrm{m} / \mathrm{s}^{2}$ and points). This way one can quickly find the daily exposure (in $\mathrm{m} / \mathrm{s}^{2}$ and points) and is also warn if EAV or ELV are exceeded. For the situations presented, the calculation is (fig. 6 and 7).

It can be seen at the bottom of fig. 6 and 7: WARNING! On the first day, the daily exposure was exceeded by $0.2 \mathrm{~m} / \mathrm{s}^{2}$ and the total exposure points by 19 points, and on the second day by $1.1 \mathrm{~m} / \mathrm{s}^{2}$, respectively by 109 points.

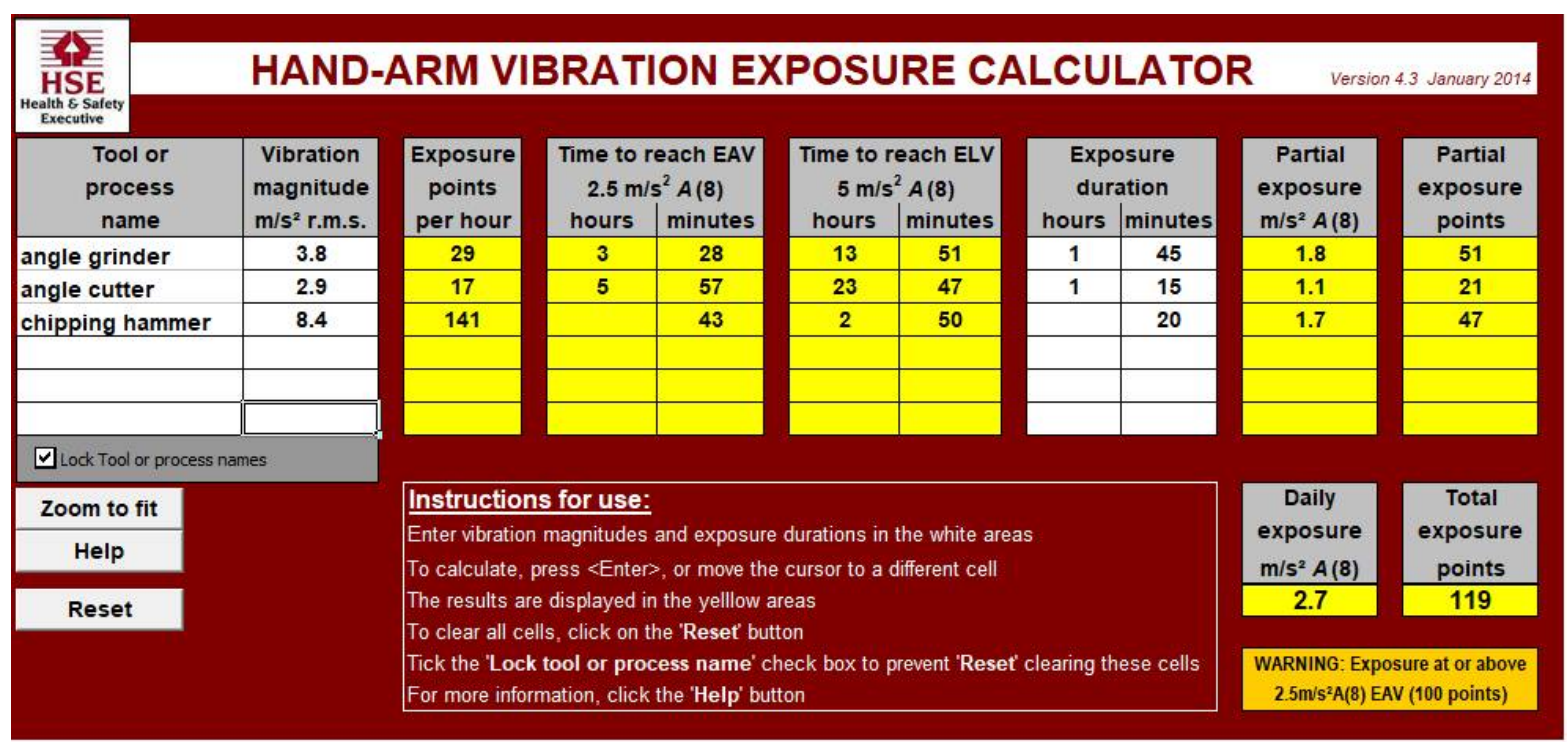

Figure 6. Hand-arm vibration exposure calculator for day 1

https://www.hse.gov.uk/vibration/hav/vibrationcalc.htm [8]

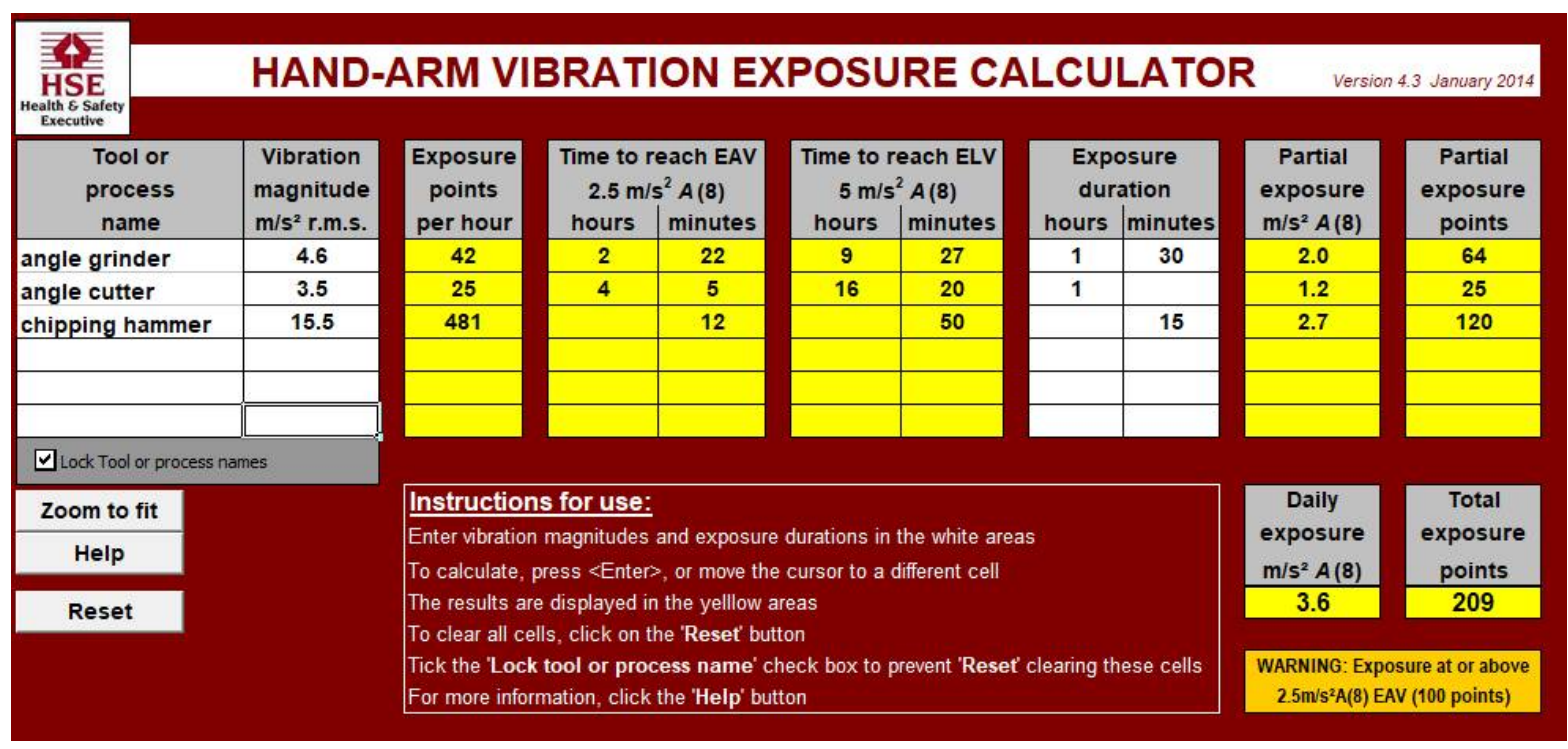

Figure 7. Hand-arm vibration exposure calculator for day 2

https://www.hse.gov.uk/vibration/hav/vibrationcalc.htm [8]

In addition to the characteristics ELV $5 \mathrm{~m} / \mathrm{s}^{2} \mathrm{~A}(8)$ for each tool and for each day. analyzed so far (partial exposure and daily From fig. 8 it can see that the tools used on day exposure), from fig. 6 and 7 also see the values 1 are better (for similar exposure times), for Time to rich $2.5 \mathrm{~m} / \mathrm{s}^{2} \mathrm{~A}(8)$ and Time to rich because the time values are higher. 


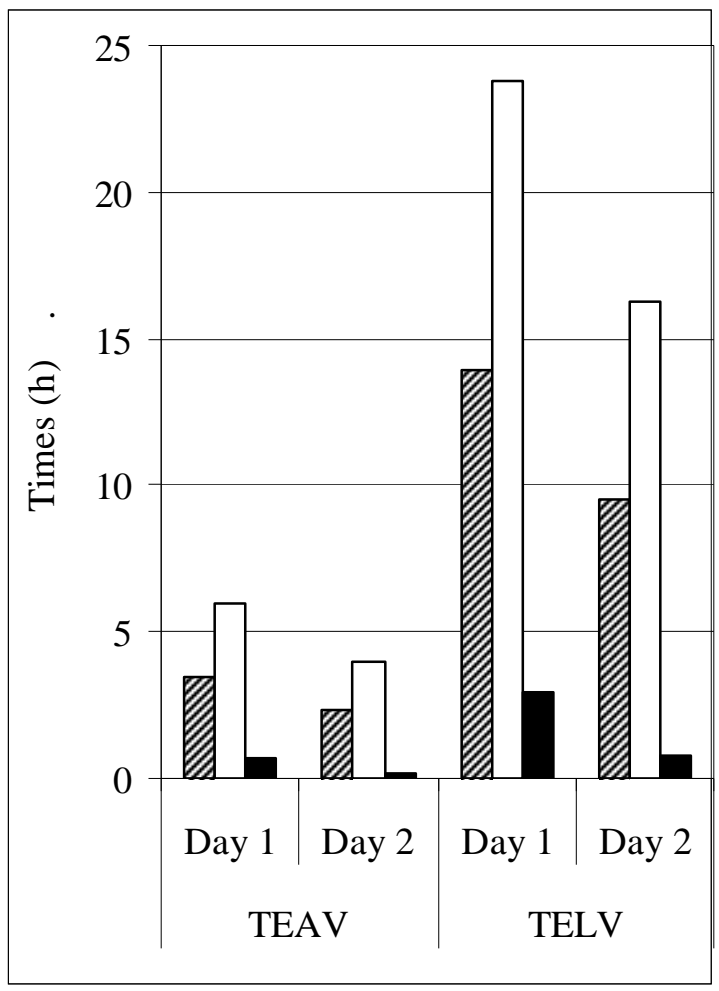

Figure 8. Variation of $\mathrm{T}_{\mathrm{EAV}}$ and $\mathrm{T}_{\mathrm{ELV}}$ for each tool and for each day. (///) - angle grinder; (口) - angle cutter; (घ) - chipping hammer

\section{CONCLUSIONS}

To find out which method is the most accurate, a parallel will be drawn between the results obtained by each method, as compared to the first method (Table. $2 \div 5$ ).

From these tables it can be seen that the deviations for partial exposure, for daily exposure, for exposure points per hour, as well as for total exposure points are very small, compared to the first method (the one in which the calculations were made step by step). Large deviations, obtained with the graphical methods e and f (grey areas) are also seen; here, quite large human errors appear because they depend on each person ability to draw, respectively to assess the objective physical values.

In conclusion, the fastest and most accurate method is the one that uses the Internet: "Hand-arm vibration exposure calculator", because it instantly gives all values of interest.

\begin{tabular}{|c|c|c|c|c|c|c|c|c|c|c|c|c|c|c|c|c|c|}
\hline \multicolumn{9}{|c|}{ Day 1} & \multicolumn{9}{|c|}{ Day 2} \\
\hline \multicolumn{3}{|c|}{$A_{\text {grin }}(8)$} & \multirow{2}{*}{\multicolumn{3}{|c|}{$\frac{\mathrm{A}_{\text {cutt }}(8)}{\text { Method }}$}} & \multirow{2}{*}{\multicolumn{3}{|c|}{$\frac{\mathrm{A}_{\text {chip }}(8)}{\text { Method }}$}} & \multirow{2}{*}{\multicolumn{3}{|c|}{$\begin{array}{l}A_{\text {grin }}(8) \\
\text { Method }\end{array}$}} & \multirow{2}{*}{\multicolumn{3}{|c|}{$\frac{A_{\text {cutt }}(8)}{\text { Method }}$}} & \multicolumn{3}{|c|}{$\mathrm{A}_{\text {chip }}(8)$} \\
\hline & Method & & & & & & & & & & & & & & & Method & \\
\hline $\mathrm{a}$ & $\mathrm{e}$ & $\mathrm{g}$ & $\mathrm{a}$ & $\mathrm{e}$ & $\mathrm{g}$ & $\mathrm{a}$ & $\mathrm{e}$ & $\mathrm{g}$ & $\mathrm{a}$ & $\mathrm{e}$ & $\mathrm{g}$ & $\mathrm{a}$ & $\mathrm{e}$ & $\mathrm{g}$ & $\mathrm{a}$ & $\mathrm{e}$ & $\mathrm{g}$ \\
\hline 1.777 & 1.75 & 1.8 & 1.146 & 1.15 & 1.1 & 1.714 & 1.7 & 1.7 & 1.991 & 2 & 2 & 1.237 & 1.2 & 1.2 & 2.74 & 3.1 & 2.7 \\
\hline$\%$ & $<1.52$ & $>1.29$ & $\%$ & $>0.35$ & $<4.01$ & $\%$ & $<0.81$ & $<0.81$ & $\%$ & $>0.45$ & $>0.45$ & $\%$ & $<2.99$ & $<2.99$ & $\%$ & $<13.1$ & $<1.45$ \\
\hline
\end{tabular}

Table 3. Results for daily exposure

\begin{tabular}{|c|c|c|c|c|c|}
\hline \multicolumn{3}{|c|}{ Day 1} & \multicolumn{3}{|c|}{ Day 2} \\
\hline \multicolumn{3}{|c|}{$\mathrm{A}(8)$} & \multicolumn{3}{|c|}{$\mathrm{A}(8)$} \\
\hline \multicolumn{3}{|c|}{ Method } & \multicolumn{3}{|c|}{ Method } \\
\hline $\mathrm{a}$ & $\mathrm{e}$ & $\mathrm{g}$ & $\mathrm{a}$ & $\mathrm{e}$ & $\mathrm{g}$ \\
\hline 2.7225 & 2.6972 & 2.7 & 3.6063 & 3.8794 & 3.6 \\
\hline$\%$ & $<0.92$ & $<0.82$ & $\%$ & $<7.57$ & $<0.17$ \\
\hline
\end{tabular}

Table 4. Results for total exposure points

\begin{tabular}{|c|c|c|c|c|c|c|c|}
\hline \multicolumn{3}{|c|}{ Day 1 } & \multicolumn{4}{c|}{ Day 2 } \\
\hline \multicolumn{3}{|c|}{ A $(8)$} & \multicolumn{4}{c|}{ A $(8)$} \\
\hline \multicolumn{3}{|c|}{ Method } & ged \\
\hline a & e & f & g & a & e & f & g \\
\hline 118.6 & 115 & 154 & 119 & 208.48 & 255 & 226 & 209 \\
\hline
\end{tabular}

Table 5. Results for exposure points per hour

\begin{tabular}{|c|c|c|c|c|c|c|c|c|c|c|c|c|c|c|c|c|c|c|c|c|c|c|c|}
\hline \multicolumn{12}{|c|}{ Day 1} & \multicolumn{12}{|c|}{ Day 2} \\
\hline \multicolumn{4}{|c|}{$\mathrm{A}_{\text {grin }}(8)$} & \multicolumn{4}{|c|}{$\mathrm{A}_{\text {cutt }}(8)$} & \multicolumn{4}{|c|}{$\mathrm{A}_{\text {chip }}(8)$} & \multicolumn{4}{|c|}{$\mathrm{A}_{\text {grin }}(8)$} & \multicolumn{4}{|c|}{$\mathrm{A}_{\text {cutt }}(8)$} & \multicolumn{4}{|c|}{$\mathrm{A}_{\text {chip }}(8)$} \\
\hline \multicolumn{4}{|c|}{ Method } & \multicolumn{4}{|c|}{ Method } & \multicolumn{4}{|c|}{ Method } & \multicolumn{4}{|c|}{ Method } & \multicolumn{4}{|c|}{ Method } & \multicolumn{4}{|c|}{ Method } \\
\hline $\mathrm{d}$ & $\mathrm{e}$ & $\mathrm{f}$ & $\mathrm{g}$ & $\mathrm{a}$ & $\mathrm{e}$ & $\mathrm{f}$ & $\mathrm{g}$ & $\mathrm{a}$ & $\mathrm{e}$ & $\mathrm{f}$ & $\mathrm{g}$ & $\mathrm{a}$ & $\mathrm{e}$ & $\mathrm{f}$ & $\mathrm{g}$ & $\mathrm{a}$ & $\mathrm{e}$ & $\mathrm{f}$ & $\mathrm{g}$ & $\mathrm{a}$ & $\mathrm{e}$ & $\mathrm{f}$ & $\mathrm{g}$ \\
\hline 50.5 & 50 & 64 & 51 & 21.0 & 20 & 21 & 17 & 47.0 & 45 & 47 & 141 & 63.4 & 65 & 81 & 64 & 24.5 & 25 & 25 & 25 & 120 & 165 & 120 & 120 \\
\hline
\end{tabular}

\section{REFERENCES}

[1] Directive 2002/44/EC on the minimum health and safety requirements regarding the exposure of workers to the risks arising from physical agents (vibrations).
[2] Guide to good practice on Hand-Arm Vibration. Nonbinding guide to good practice with a view to implementation of Directive 2002/44/EC on the minimum health and safety requirements regarding the exposure of workers to the risks arising from physical agents (vibrations). 12/06/2006 
[3] EN ISO 5349-1:2001 Mechanical vibration Measurement and evaluation of human exposure to handtransmitted vibration - Part 1: General requirements

[4] ISO 8662 series, Hand-held portable power tools Measurement of vibrations at the handle

[5] IEC 60745 series, Hand-held motor-operated electric tools. Safety

[6] EN ISO 5349-2:2001 Mechanical vibration Measurement and evaluation of human exposure to hand- transmitted vibration. Part 2: Practical guidance for measurement at the workplace

[7] CEN/TR 15350:2006, Mechanical vibration Guideline for the assessment of exposure to handtransmitted vibration using available information including that provided by manufacturers of machinery [8] Hand-arm vibration exposure calculator https://www.hse.gov.uk/vibration/hav/vi brationcalc.htm 